\title{
A IMAGEM DA TEORIA E DA PRÁTICA DE ENFERMAGEM EM FILMES: UMA ANÁLISE À LUZ DOS DEPOIMENTOS DOS ESTUDANTES
}

\author{
Carmen Maria dos Santos Lopes Monteiro Dantas da Silva ${ }^{1}$, Neiva Maria Picinini Santos²
}

\begin{abstract}
RESUMO: O filme como estratégia de aprendizagem proporciona aos estudantes o conhecimento teórico-prático. Os objetivos foram descrever as contribuições do uso do filme como estratégia de aprendizagem e analisar o significado das contribuições do filme na aprendizagem do estudante de enfermagem. Pesquisa qualitativa em que os dados atenderam à análise temática: pré-análise - leitura flutuante e recorrente; exploração do material - codificação; agrupar por semelhança; o surgir das unidades; tratamento dos resultados e interpretação; depoimentos articulados a autores que abordam a temática e ao referencial teórico - conceito, modos de operar a ideologia segundo Thompson. Como unidade temática as contribuições e implicações da estratégia do filme na aprendizagem do estudante de enfermagem e os tópicos: o estímulo que conduz o estudante de enfermagem a exercitar o pensamento; a imagem da teoria e da prática de enfermagem; a intencionalidade do filme como estratégia de aprendizagem. Todos os sujeitos concluíram que o filme contribui na formação. PALAVRAS-CHAVE: Enfermagem; Aprendizagem; Estratégias; Filmes.
\end{abstract}

\section{THE IMAGE OF NURSING THEORY AND PRACTICE IN THE MOVIES: ANALYSIS BASED ON STUDENTS'TESTIMONIALS}

\begin{abstract}
The movies as a learning strategy, enables students to access the theoretical and practical knowledge. The objectives were to describe the contributions of the use of the movies as a strategy for learning, and analyzing its significance of the contributions on the nursing student's learning process. It's a qualitative research, in which data were suitable to the thematic analysis: pre-analysis - flowing and recurrent reading; exploitation of material - coding; grouping by similarity; the units arise; processing and interpretation of results; the articulation of statements and author's speeches that address the theme, and the theoretical framework - concepts, methods of operating the ideology according to Thompson. As thematic unit: contributions and implications of the movies strategy in the nursing student's learning. The topics: the motivation that leads the nursing student to reflection, the image of nursing theory and practice, the intent of the movies as a learning strategy. All research subjects concluded that the movies contribute to training.
\end{abstract}

KEYWORDS: Nursing; Learning; Strategies; Movies.

\section{LA IMAGEN DE LA TEORÍA Y DE LA PRÁCTICA DE LA ENFERMERÍA EN PELÍCULAS: UN ANÁLISIS A LALUZ DE LAS DECLARACIONES DE LOS ESTUDIANTES}

RESUMEN: La película como estrategia de aprendizaje proporciona a los estudiantes el conocimiento teórico-práctico. Los objetivos fueron describir las contribuciones de la utilización de la película como una estrategia de aprendizaje y analizar el significado de las contribuciones de la película en el aprendizaje del estudiante de enfermería. Investigación cualitativa, en la que los datos atendieron al análisis temático: pre-análisis - lectura flotante y recurrente; explotación del material - codificación; agrupar por similitud, el surgimiento de las unidades, tratamiento de los resultados e interpretación; declaraciones articuladas a autores abordan la temática y al referencial teórico - concepto, modos de operar la ideología según Thompson. Como unidad temática las contribuciones e implicaciones de la estrategia de la película en el aprendizaje del estudiante de enfermería y los tópicos: el estímulo que lleva al estudiante de enfermería a ejercitar el pensamiento; la imagen de la teoría y de la práctica de la enfermería, la intención de la película como una estrategia de aprendizaje. Todos los sujetos concluyeron que la película contribuye en la formación.

PALABRAS CLAVE: Enfermería; Aprendizaje; Estrategias; Películas.

${ }^{1}$ Enfermeira e Advogada. Mestre em Enfermagem pela Escola de Enfermagem Anna Nery-EEAN-UFRJ. Professora do Curso de Graduação em Enfermagem e do Curso de Graduação em Medicina do Centro Universitário Serra dos Órgãos-UNIFESO-RJ

${ }^{2}$ Enfermeira. Doutora em Enfermagem pela EEAN-UFRJ. Professor Adjunto do Departamento de Metodologia em Enfermagem da EEAN-UFRJ.

Autor correspondente:

Carmen Maria dos Santos Lopes Monteiro Dantas da Silva

Rua Monte Líbano, 53 - 25953-030 - Teresópolis-RJ

Recebido: 17/06/09

Email: carmenmarielouis@hotmail.com

Aprovado: 25/06/09

Cogitare Enferm 2009 Abr/Jun; 14(2):332-9 


\section{CONSIDERAÇÕES INICIAIS}

Envolta em memórias, descubro entre papéis amassados e amarelados, desenhos, imagens e retratos de minha história que resgatam sentidos, símbolos e significados para os dias de hoje. Faço-o sustentada em conceitos como o ensino e a aprendizagem na (re)construção do conhecimento, quando o permear de culturas se vinculam ao processo conhecido como educação. Assim, não posso apagar as minhas inquietações acerca do processo educativo, no sentido de pouco ter podido questionar durante a minha aprendizagem, muito menos problematizá-la, pois o conhecimento era colocado dentro de mim de uma forma estática, linear e quase "perfeita”.

A boa Educação fortalece a minha convicção de que são necessárias estratégias de aprendizagem para que o estudante do Curso de Enfermagem se motive na busca do saber, obtendo o profundo preparo para a profissão, pois elas auxiliam nas minhas escolhas, discernindo o que fazer ou não fazer.

No processo de formação dos enfermeiros, um filme pode ser rica estratégia de aprendizagem, por produzir formas simbólicas como gestos, expressões e imagens que estimulam a participação maior dos estudantes. Desta forma, o objeto para este estudo foi o filme como estratégia de aprendizagem para o estudante de Enfermagem.

As contribuições do estudo irão permitir usar o filme como estratégia de aprendizagem para construir o perfil do estudante, para ser Enfermeiro de modo inovador e inédito; prestar subsídios para um estudo mais dinâmico, imbuído de qualidade ao mediar práticas sociais e culturais; estimular e favorecer o aprendizado no evoluir da formação para enfermeiros na sua historicidade e dinamicidade com o fito de desenvolver o "aprender a aprender".

Na continuidade do estudo desenvolvido, vinculo ao presente texto o segundo tópico: A imagem da teoria e da prática de enfermagem da Dissertação de Mestrado que se intitula, $O$ filme no ensino de graduação em enfermagem: contribuições de uma estratégia de aprendizagem.

Os objetivos desta pesquisa foram: Descrever as contribuições do uso do filme como estratégia de aprendizagem; Analisar o significado das contribuições do filme na aprendizagem do estudante de enfermagem.

\section{DESCRIÇÃO METODOLÓGICA}

Trata-se de um estudo qualitativo, em que o cenário foi um Centro Universitário Privado do Município de Teresópolis, no Estado do Rio de Janeiro. Os sujeitos envolvidos foram oito estudantes do Curso de Graduação em Enfermagem do $4^{\circ}$ e $5^{\circ}$ períodos. Embora o filme seja um recurso utilizado em outras disciplinas, o propósito da pesquisa focou os estudantes que se situam no meio do curso, visto que já passaram por disciplinas que se valeram do filme e, além disso, supõe-se que estes já possuem mais conhecimentos teórico-práticos.

O procedimento metodológico utilizado na coleta de dados foi a entrevista semi-estruturada, e estas foram realizadas no período de maio a agosto de 2007. Cada entrevista teve em média a duração de trinta minutos e foi realizada individualmente

Para a execução deste procedimento foram fornecidas aos participantes informações e esclarecimentos acerca dos objetivos deste trabalho e solicitado seu consentimento em participar, de acordo com a Resolução n. 196/96 do Ministério da Saúde ${ }^{(1)}$. O projeto de pesquisa foi aprovado pelo Comitê de Ética em Pesquisa da respectiva instituição, com o n. 078/06.

Os depoimentos foram gravados em fitas eletromagnéticas sendo depois transcritas na íntegra, preservando a fidedignidade das informações. Para manter o sigilo e o anonimato, os estudantes foram identificados por pseudônimos com nomes de anjos: Habuhiah, Asaliah, Mikael, Mihael, Hariel, Mitzrael, Anauel e Nemamiah ${ }^{(2)}$.

Na análise dos dados foi utilizado o método da análise temática, que se desenvolveu em três etapas: Pré-análise: leitura flutuante e recorrente das entrevistas; Exploração do material: fase que trata de operar a codificação, ao agrupar os dados por grupos de semelhança e, conseqüentemente, obtendo as unidades temáticas; Tratamento dos resultados obtidos e interpretação: nesta fase os depoimentos são analisados e se constroem articulações com autores que tratam do tema do estudo como também do referencial teórico - conceito e os modos de operacionalização da ideologia ${ }^{(3)}$.

$\mathrm{O}$ autor esclarece que as estratégias possibilitam alcançar os modos de operacionalização da ideologia, na qual a legitimação traduz relações legítimas de domínio, devendo ser respeitadas e apoiadas. Correspondem-lhe como estratégias a racionalização que produz a forma simbólica na construção do raciocínio que tentará defender e persuadir tudo que é digno de apoio, e a universalização que através de acordos institucionais serve aos interesses de alguns indivíduos ampliando-os aos interesses de todos. A narrativização faz com que as formas simbólicas "mergulhem" na 
história e tratem do presente ${ }^{(3)}$.

O segundo modo, a dissimulação, que nos diz que as relações de poder para serem efetivadas são ocultadas da atenção das pessoas, tem como estratégias: deslocamento, porque as formas simbólicas são usadas para se referirem a um objeto ou pessoa com base numa linguagem simbólica; a eufemização, que valoriza de forma positiva as relações sociais e as instituições ao mudar o sentido das ações. Por fim, tropo dissimula as ações de poder e as formas simbólicas são usadas de forma figurativa.

O terceiro modo apresentado pelo autor é a unificação. As relações de dominação são entendidas na construção de um nível simbólico que une os participantes e forma coletividades, independente das diferenças que existam entre eles. A este correspondem as seguintes estratégias: padronização, na qual as formas simbólicas são adaptadas a um referencial padrão aceitável; e simbolização da unidade, que consta em construir símbolos de unidade, identidade e de identificação coletiva para se difundirem num ou em vários grupos.

No quarto modo, a fragmentação, as relações de poder não unificam as pessoas num coletivo, pelo contrário separam-nas dos indivíduos que possam vir representar ameaça aos grupos dominantes. Usa como estratégias a diferenciação e o expurgo do outro. Na diferenciação, as formas simbólicas se fundamentam nas diferenças entre as pessoas e grupos e se apóiam nas características que os desunem. No expurgo do outro se constrói um inimigo interno ou externo que se investe de caráter ameaçador para o qual os indivíduos são chamados a resistir ou o expurgam coletivamente.

O quinto e último modo a reificação, pois são estabelecidas e mantidas relações de dominação que reproduzem situação de maneira natural, ao excluir o caráter social e histórico. Compõem as suas estratégias a naturalização, a eternalização, a nominalização e a passivização. A naturalização representa um estado de coisas, criação social e histórica, podendo ser tratada como um acontecimento natural ou o resultado inevitável de características naturais. Na eternalização os fenômenos sócio-históricos se apresentam permanentes, imutáveis e deixam de ter característica histórica. A nominalização se parte de sentenças, descrições da ação e dos participantes nelas envolvidos que são transformados em nomes. A passivização é uma estratégia que acontece quando os verbos são colocados na voz passiva.

Assim, uma parte da análise das falas proferidas pelos estudantes em suas entrevistas é apresentada constituindo-se a unidade temática: As Contribuições e as Implicações da Estratégia do Filme na Aprendizagem do Estudante de Enfermagem. Esta se compôs dos seguintes tópicos: O estímulo que conduz o estudante de enfermagem a exercitar o pensamento, quanto às contribuições do filme como estratégia de aprendizagem os entrevistados mencionaram: fixar a atenção da aprendizagem; estimula a aprender a pensar; melhora a visão de mundo; estimula a sensibilidade; aumenta a percepção e a criatividade; desperta o senso crítico e reflexivo e desenvolve a iniciativa. A imagem da teoria e da prática de enfermagem, sendo que neste tópico dá-se primazia às contribuições da estratégia em uso: favorecer a compreensão da teoria; proporciona a percepção da prática de enfermagem; possibilita a revelação de aspectos do cotidiano hospitalar.

Ainda, favorece a articulação da teoria à prática profissional; possibilita a aplicação do conteúdo teórico à prática de enfermagem; oferece maneiras de atuação do estudante de enfermagem frente à prática profissional; estimula o senso de grupo; predispõe à assimilação do conhecimento pessoal e profissional; possibilita ao estudante se colocar no lugar do outro; proporciona ver o cliente como um todo; favorece o conhecimento acerca da história da profissão. Por fim, a intencionalidade do filme como estratégia de aprendizagem, destacando como contribuições: a intencionalidade do filme e o filme como instrumento alternativo da educação.

\section{RESULTADOS E ANÁLISE}

A destacar as contribuições do filme como estratégia de aprendizagem, integradas no segundo tópico “A imagem da teoria e da prática de enfermagem" temos neste o benefício advindo do uso da estratégia do filme, quando este favorece a compreensão da teoria através do poder da imagem, como se ilustra abaixo:

A imagem ajuda muito mais a fixar o conhecimento [...] porque o cérebro acaba aliando a teoria que foi dada a uma cena, a um gesto. Facilita bastante. A expressão facial, os gestos do cliente que não fala, também contribuem. [...] qualquer filme, qualquer imagem, você educa, mais o seu olhar para coisas sutis, que normalmente passariam despercebida (Anauel). 
O uso do filme proporciona aos estudantes, através da visão, um entendimento extraído pela compreensão da teoria de forma mediata quando o olhar ajuda a encontrar na mente, o pensar adequado conforme $\mathrm{o}$ aprendizado a ser efetuado, diante apenas da exposição teórica. Além disso, resulta pela estratégia do filme um compreender maior uma vez que a este se associa o detalhe, a sutileza para situações mais particulares, algumas mais difíceis de serem notadas sem uma imagem mais concreta caso esta viesse a ser o resultado de uma criação mental.

Uma imagem, visão, imaginar-criar são formas simbólicas que vão permear constantemente o aprendizado dos alunos ao instigar a demonstração de uma prática diária levá-los a compreender que o filme facilita o vínculo entre o que se vê e o que se aprende para saber agir. É interação compreender a teoria através do fluxo de comunicação, predominantemente em mão única, na qual as respostas possíveis são restritas à compreensão do receptor ${ }^{(3)}$. De fato o estudante pela experiência que vai absorvendo do filme como veículo de aprendizagem, aprende a lidar com os momentos de maior dificuldade referentes a uma temática, quando a imagem como forma simbólica ajuda no significado.

Desta forma, entende-se que a estratégia pode ser uma contribuição positiva para o que destaco, o modo de operação de ideologia de Thompson, a Unificação pela união estabelecida entre os estudantes na compreensão uniforme por parte destes de uma prática profissional mediada pelo uso do simbolismo do filme, quando se recorre à estratégia de Padronização. Esta permite a aceitação de trocas simbólicas como padrão já que o filme remete rápido à realidade profissional fazendo com que o aprendizado teórico seja aplicado.

Os depoimentos de três estudantes remetem a outra contribuição da estratégia de aprendizagem que favorece a articulação da teoria à prática:

\section{[...] a partir do momento que eu vejo, tenho o} conhecimento teórico, e científico que vai articular com certeza na prática, [...] são as várias visões do filme que já vai articulando, se fosse assim, se fosse daquele jeito (Mikael).

A partir do filme conseguimos aliar o que foi dado em sala de aula, em termos de teoria, com o que podemos chegar a ver na prática (Anauel).

O filme como estratégia para o aprendizado em enfermagem conecta facilmente os indivíduos num mundo de relações, e os estudantes ao percebê-lo distinguiram com clareza o significado da sua utilidade ao articulá-lo à prática profissional, demonstrando a participação deste ao adicionar à aprendizagem situações que dificilmente seriam concebidas sem a sua ajuda. Em contraponto, com a busca do conhecimento e o interesse em aprender, o estudante em vias de ser enfermeiro precisa estar bem atento para que possa aprender a lidar com o que não conhece.

Para isso, tem que saber processar todo o tipo de conhecimento aprendido, tenha este sido absorvido através de aulas teóricas ou mediado pelo uso de um filme como estratégia para a visualização direta do real. Com certeza deverá estar mais desperto para travar um relacionamento mais tranquilo com símbolos, significados e extrair destes sentidos que, estimulados pelo olhar e percebidos na memória visual, faculte automaticamente a capacidade, de reinterpretar o que observa com base em seus conhecimentos teóricoprático construídos.

O fato de nos colocarmos como receptores de um evento comunicacional traduz com transparência a linguagem de um mundo ideológico e de poder, ao gerar múltiplos sentidos que ao serem recuperados pelo receptor em uma análise, torna-se necessário que eles ganhem forma de sentidos produzidos que definam relações e identidades pessoal e sociais ${ }^{(4)}$. Neste sentido, as formas simbólicas variam entre nãolingüísticas ou quase-linguísticas, sendo uma imagem visual que, ao ser produzida pelo sujeito e reconhecida por este como construto significativo, e através destas as pessoas se comunicam, conservam e eternalizam conhecimentos e atitudes no trâmite de suas existências ${ }^{(3)}$.

A utilização do filme em aula traz à presença a estratégia da Racionalização, e através desta ação os estudantes são conduzidos ao aprendizado e a situações concretas em cenário da prática.

Outro ponto de interesse trouxe uma abordagem digna de registro quando se refere à fala de um dos estudantes no que concerne à interação da estratégia e seu aprendizado, o que possibilita a aplicação do conteúdo teórico à prática de enfermagem:

[...] você assistiu o filme, vem aquela imagem, então tudo o que eu vou fazer é levar para a minha profissão, [...] você tem aquela experiência, vem na cabeça, então vou agir, diante daquilo que eu assisti e me foi passado. [...] acho muito importante 
o trabalho em equipe, porque muitas vezes o enfermeiro sozinho não faz nada, tem que ser o enfermeiro, médico, fisioterapeuta a nutricionista todos trabalhando em conjunto [...] o olhar holístico, [...], o filme sempre trás esse olhar. Porque você olha aquilo que o professor quer que você olhe, aquilo numa direção, e não é isso, a idéia é olhar com várias visões, além do indivíduo [...] (Mikael).

A destacar as dificuldades enfrentadas pelos discentes durante a vida acadêmica, principalmente na iniciação à prática hospitalar em que o contacto com os clientes os coloca na expectativa de como fazê-lo, qual será a reação daquele sujeito adoecido, os sentimentos afetados por se encontrar distante da família ou do trabalho. Como contornar esta série de problemas, detectá-los num cliente que não possui desenvoltura para o diálogo, não se comunica devido à patologia, alguém que não conheço devidamente e ainda acompanhada de dor física ou emocional. É muito difícil para o estudante nesta fase do curso solucionar tantos obstáculos diante da tela hospitalar, devendo pleitear apoio e aprendizado junto à estratégia a fim de somar tal como menciona o depoente um olhar "além do indivíduo", o que significa que o filme contribui subsidiando múltiplas perspectivas de ação, principalmente quando estas vêm através das imagens do filme.

A compreensão de uma prática tenta romper com a idéia de professor como único capaz de distribuir um saber pronto e acabado, e deve, sim, abrir as possibilidades para que o estudante faça a construção do aprendizado ${ }^{(5)}$. De acordo com o que estou familiarizada na minha relação com os estudantes, verifico que estes vivem apressados e pensativos com o cenário prático, tentam a todo o custo abarcar o mundo no ímpeto. As situações não podem ser entendidas nem desempenhadas em ritmo acelerado, porque a compreensão do saber pela união da teoria e prática se reveste da crescente responsabilidade em formar profissionais zelosos, de forma que cresçam em personalidade, se emancipem e atinjam a autonomia que permeia todo o viver em grupo.

As situações apresentadas sob o condão dos modos operantes da ideologia estabelecem relações de poder e trazem para o estudo o modo da Unificação, correlacionando sustentação igualitária a todos, o que justifica uma suposta união sem questionamento de poder $^{(3)}$. A acrescentar a estratégia de estandardização no que cabe a um trabalho multidisciplinar realizado por uma equipe de profissionais na área da saúde, reunindo esforços e padronizando atitudes ao visar a manutenção de poder e a simbolização de unidade que pode reunir símbolos que reforçam a valorização dos dominantes com suas concepções e crenças.

Outra contribuição é apresentada por dois entrevistados quando nos trazem os modos de atuação do estudante de enfermagem frente à prática profissional:

O filme mostra que a postura, é muito importante para o profissional [...] vários jeitos e de vários âmbitos (Mikael).

[...] vejo como uma base, a base para que você tenha tudo que está pretendendo, pelas atitudes [...] você tem um link, elo de ligação, e liga isso através das atitudes que são vistas, por vezes pode não estar tão bem explicita, mas você consegue enxergar [...] quanto ao assistir ao filme, o que modificaria o que para mim seria bom [...] (Asaliah).

No contexto do presente estudo, a estratégia em uso divulgada na aprendizagem dos sujeitos participa na compreensão e na facilidade de abordar o cotidiano no lançar-se mãos do filme por estimular outros aprendizados, já que ele se define como um processo em crescimento sob o poder de se transformar e se revelar cada vez mais. O filme retrata-os e por este motivo torna-os presentes e reveladores aos olhos dos depoentes que os percebem úteis e necessários à prática de uma atividade e uma suposta postura profissional a serem desenvolvidas e compreendidas no percurso do curso de graduação em enfermagem.

À medida que a formação vai avançando, observo que os depoentes vão adquirindo a real noção do movimento do filme associado ao que necessitam para evoluir em sua caminhada acadêmica, objetivando serem enfermeiros. Aliás, o filme é o tipo de alimento que o estudante necessita para entender que tudo o que aprende de modo inovador deve ser aplicado de igual forma. Embora caiba a cada um fazer a diferença, como ficou bem evidente na fala de Asaliah quando diz que:

[...] vejo como uma base, a base para que você tenha tudo que está pretendendo, pelas atitudes [...].

Os discursos dos estudantes revelam 
flexibilidade de raciocínio, que emerge da aprendizagem mediada pela estratégia em foco, porque não foi um conhecimento memorizado, encaixado sob pressão do professor mas, ao invés, este foi construído pela participação ativa dos sujeitos ao quererem se aperfeiçoar sempre mais, quando um deles salienta:

\section{[...] o que modificaria o que para mim seria bom [...].}

O filme encerra vários vieses de discussão que os estudantes podem seguir para que possam obter um aprendizado mais amplo quando o fazem sob o ponto de vista da comunicação, informação, distração, publicidade, propaganda e educação( ${ }^{(6)}$. Com certeza, no campo de proporcionar aprendizado o filme é a sustentação para que se obtenham novos horizontes, uma vez que acordam para tantos aspectos que nem conheciam. É o "link”, o meio de informação em que os assuntos desconhecidos se tornam comuns e familiares e contatá-los à priori, será benéfico para que o tempo os ajude a lidar com situações diferentes.

De fato, cabe salientar que as atitudes, o olhar e as posturas descrevem formas simbólicas que podem influenciar significativamente formas de interação em que os indivíduos se comunicam num contínuo formar de relações sociais (maneiras de agir), quando se percebe a ocorrência de modos de operação ideológica como a Unificação ${ }^{(3)}$. Nesta há a distinguir o sentido de interação do estudante com ele mesmo no aperfeiçoar permanente como pessoa humana, participando de múltiplas redes sociais no ambiente hospitalar. Como estratégia tem-se a Simbolização de Unidade através da qual os estudantes estabelecem relações afins objetivando o aprendizado e oportunidades dispares permeadas de experiências, [...] vários jeitos e de vários âmbitos nos limites de suas funções, como sujeitos ainda em formação visando uma profissão.

Outra contribuição do filme como estratégia de aprendizagem é que estimula o senso de grupo, sendo apresentado por três dos oito entrevistados:

Primeiro o aumento do contacto interpessoal, pois eu vejo um distanciamento dos profissionais que compõem a equipe [...] com a visualização do filme eu penso que fica mais fácil, aplicar no dia a dia o que ele mostra, pois, revela muito a humanização [...] a relação enfermeiro-equipe, tem uma repercussão positiva [...] ao ter como qualidade, seria o que diverge um pouco nos dias atuais, a questão humana [...] os demais profissionais observam se você é capacitado, para estar discutindo com você as questões relevantes acerca do cliente, você não é uma mera peça de equipe, faz parte dela, no objetivo comum que é dar, assistência ao cliente. Bom o filme vai auxiliar ao favorecer que o aluno capte essa informação de uma maneira mais rápida e prática [...] (Mihael).

No cotidiano dos estudantes os aspectos humanos interagem com eles a todo o momento pelo que a aprendizagem precisa de dar primazia e poder à construção a serviço do cuidar. Pela leitura dos depoimentos, estes articulam a estratégia do filme à proximidade humana e profissional por entenderem que o senso de grupo é primordial no ambiente de trabalho, entre colegas, na equipe profissional. Evidencia-se no entender dos estudantes como aspecto importante, já que o filme os remete à unidade, conduzindo-os a diferentes modos de atuação no exercício da enfermagem.

Entretanto, ansiedade, nervosismo e medo estão presentes em alguns estudantes, principalmente quando desempenham procedimentos de enfermagem ${ }^{(7)}$. Como também, no interagir da equipe, que se compõem por grupos de trabalho, pois o enfermeiro deverá promover sempre bons relacionamentos construindose como um profissional mais humano e completo.

É deveras preocupante a proximidade construída nestes termos, mas quando releio os autores ${ }^{(8)}$ entendo melhor o que foi narrado, embora não o aceite, pois ampliam a construção da aprendizagem ao abordá-la do seguinte modo:

[...] o conceito de processo de construção da aprendizagem que se dá nas relações do sujeito, consigo mesmo e com os outros, as quais processam-se no contexto social e institucional, situado e situante, está ligado a toda ação-reflexão, construção-comunicação, produção-relação, que envolvam a aprendizagem como processo de mudança, transformação do sujeito e do meio por intermédio das relações sociais ${ }^{(8: 28)}$.

Portanto, relativos à indagação, continuo junto às autoras concordando com estas que todos nos mantemos na construção de um aprendizado, de um modo coletivo, para que em igualdade de circunstâncias, em grupo, nos façamos presentes, embora em estágios de maturação e desenvolvimento diversos, em que as diferenças permanecem próprias da origem humana. Assim, identifico o modo operacional da ideologia, a Unificação, através das estratégias de Simbolização da 
Unidade e Padronização. Pela Unificação opera-se a ideologia através da constituição de uma base comum a todos os sujeitos, de modo a justificar a união entre eles e não o questionamento de poder.

Assim, quando o filme permeia aprendizagem ao agregar o coletivo, fortalece o senso de grupo na medida em que as diferenças são atenuadas pelo diálogo, partilha de experiências e permuta de conhecimento. O senso de grupo se constitui livremente sem imposições ou forças dominantes uma vez que a aprendizagem leva a um interesse comum e uniforme.

Outro aspecto destacado como contribuição do filme como estratégia de aprendizagem é o ver o cliente como um todo:

Então eu acho assim, se eu fosse professora, hoje em dia com certeza, eu traria o filme, como forma de ensino [...] visando um todo, por que o ser humano não é uma máquina a ser consertada por partes [...] ele é um todo, sentimento, coração e comunidade-sociedade, todos os aspectos. O filme consegue trabalhar o todo [...], por isso eu gosto do filme (Mikael).

[...] quando você vê o filme em uma disciplina, você fala [...] que interessante [...] mas não pensa em tanta contribuição relacionada, agora até que dá para valorizar, mais ao vê-lo, vai relacionar todos esses aspectos (Hariel).

Nós devemos olhar o indivíduo, como um todo, de uma maneira completa (Nemamiah).

Os estudantes demonstram suas opiniões acerca da aprendizagem, quando o enfoque é sempre o cliente, e o fazem com dedicação ao considerá-lo como um todo, quando o fazem com clareza e retratam a importância do momento. Assim, vivenciam a inversão de papéis sendo docentes e discernem entre o desenvolvimento da aprendizagem mediada pelo uso da estratégia e a repercussão desta na assistência com o cliente. O momento das falas dos depoentes enfatiza um discurso promissor acerca do interesse e valor que o filme possui ou pode vir a representar. Assim, conteúdos personalíssimos que deixam registrado o significado do filme em correlação com o conhecimento obtido pelos estudantes, ao passar com mais permeabilidade, aprendizagem como uma estratégia digna, para que o cliente venha a ser alcançado no todo, ou seja, em sua integralidade, por estes e outros que venham abraçar firmes a profissão de enfermagem.

Muito interessante a fala de Mikael, bem espontânea quando incorpora o perfil de professora e verbaliza sem ser resposta a pergunta alguma o seu sentir em relação ao filme. Assim, faz supor que este predispõe à abertura e permite que as pessoas deixem fluir os seus sentimentos, às vezes enraizados dentro de si, dando a oportunidade de que os outros tenham a ideia, de que os colegas, por exemplo, são máquinas e como tal despojados de emoções e vontades, em suma, desintegrados dentro de si mesmos. Acerca do processo de formação dos sujeitos na enfermagem, esclarecem as autoras ${ }^{(9)}$ que o sujeito da práxis, ou seja, o estudante-enfermeiro dirige seus atos a certos objetos, idéias, imagens de forma que os transformem de acordo com as finalidades.

Desta forma, a estratégia suscita um ambiente prazeroso de (re)significados para o estudante, podendo refletir com esmero acrescentando múltiplas contribuições. Ainda constato que o filme cria o espaço de discussão e de análise no liame da teoria e prática, traduzindo-se uma unidade de pensamento pela semelhança e conformidade de idéias quando o aprender se edifica acima de tudo na valorização do estudante como um todo e assim traduzido:

O filme consegue trabalhar o todo [...], por isso eu gosto do filme.

O conhecimento, por não ser estático, encontrase em contínua construção, sendo de primordial pertinência motivar os estudantes para a aprendizagem, unindo a estratégia como forma de comunicação, para que o envolvimento integral dos mesmos seja incorporado por eles ao assumirem-se responsáveis e comprometidos com o que devem aprender.

\section{CONSIDERAÇÕES FINAIS}

Cabe salientar, neste momento, que o filme como estratégia de aprendizagem para o estudante contribui como sendo a imagem da teoria e da prática de enfermagem, já que a atenção o motivou a aprender a pensar. Sabe-se que no momento da prática hospitalar os estudantes experimentam, quando direcionados ao contato com os clientes, dificuldades de atuação, quando se paralisam por insegurança e medo diante da situação humana daquele que é cuidado.

Entretanto, como se encontrassem o significado mediado da teoria-prática, a maioria dos depoentes 
deste estudo nos conduz à imagem da teoria e da prática de enfermagem para identificar a percepção dessa prática, perpassada pela imagem do filme. Todavia, não menos significativo, apesar de representar uma minoria, outras contribuições afloram como: articulação da teoria à prática; favorecer a compreensão da teoria; maneiras de atuação frente à prática dos sujeitos entrevistados que acabam por se retratar pelo filme e fazem deste o veículo eficaz para a aprendizagem. Assim, o uso do filme proporciona e dá forma à teoria pela imagem na prática, na visualização do cenário profissional.

\section{REFERÊNCIAS}

1. Ministério da Saúde (BR). Conselho Nacional de Saúde. Diretrizes e normas regulamentadoras de pesquisa envolvendo seres humanos. Resolução n. 196, 10 de outubro de 1996. Brasília; 1996.

2. Arruda B, Grzich M. Anjos: tudo o que você queria saber. São Paulo: Comunicação Três, 1995.

3. Thompson JB. Ideologia e cultura moderna. $5^{\mathrm{a}}$ ed. Rio de Janeiro: Vozes; 2002.

4. Pinto MJ. Comunicação e discurso: introdução à análise de discursos. $2^{\mathrm{a}}$ ed. São Paulo: Hacker; 2002.

5. Neto AFP. História e cinema em videocassete: reflexões em torno de uma didática. Ciência e Cultura. 1989 41(9): 884-887.

6. Carmo L. O cinema do feitiço contra o feiticeiro [periódico na Internet]. Revista Iberoamericana de Educacion, Espanha. 2003 [acesso em 2007 Jun 27] 32. Disponível: http://www.rieoei.org/.

7. Costa AJ. A relação professora-aluna de graduação em enfermagem: revelando as estratégias de ensinoaprendizagem [dissertação]. Rio de Janeiro (RJ): Escola de Enfermagem Anna Nery, Universidade Federal do Rio de Janeiro; 2005.

8. Dilly CML, Jesus MCP de. Processo educativo em enfermagem. São Paulo: Robe; 1995.

9. Martins I, Gouvea G, Piccinini C. Aprendendo com imagens [periódico na Internet]. Ciência e Cultura. 2005 [acesso em 2006 Out 11] 57(4): 38-40, 2005. Disponível: http://cienciaecultura.bvs.br/scielo. 